\title{
Molecular Characterization of Burkholderia cepacia Complex Isolates Causing Bacterial Fruit Rot of Apricot
}

\author{
Bin $\mathrm{Li}^{1}$, Yuan Fang ${ }^{1,4}$, Guoqing Zhang ${ }^{1}$, Rongrong $\mathrm{Yu}^{2}$, Miaomiao Lou ${ }^{1}$, Guanlin Xie ${ }^{1 *}$, Yanli Wang ${ }^{3}$ and \\ Guochang Sun ${ }^{3 *}$ \\ ${ }^{1}$ State Key Laboratory of Rice Biology, Key Laboratory of Molecular Biology of Crop Pathogens and Insects, Ministry of \\ Agriculture; Institute of Biotechnology, Zhejiang University, Hangzhou 310029, China \\ ${ }^{2}$ Zhejiang University of Technology, Hangzhou 310032, China \\ ${ }^{3}$ Zhejiang Academy of Agricultural Sciences, Hangzhou 310021, China \\ ${ }^{4}$ College of Chemistry and Life Sciences, Zhejiang Normal University, Jinhua 321004, China \\ (Received on May 27, 2010; Accepted on July 26, 2010)
}

\begin{abstract}
The Burkholderia cepacia complex isolates causing bacterial fruit rot of apricot were characterized by speciesspecific PCR tests, recA-HaeIII restriction fragment length polymorphism (RFLP) assays, rep-PCR genomic fingerprinting, $\operatorname{rec} A$ gene sequencing, and multilocus sequence typing (MLST) analysis. Results indicated that the isolates Bca 0901 and Bca 0902 gave positive amplifications with primers specific for $B$. vietnamiensis while the two bacterial isolates showed different $\operatorname{rec} A$ RFLP and rep-PCR profiles from those of $B$. vietnamiensis strains. In addition, the two bacterial isolates had a higher proteolytic activity compared with that of the non-pathogenic $B$. vietnamiensis strains while no $\operatorname{cbl} A$ and esmR marker genes were detected for the two bacterial isolates and $B$. vietnamiensis strains. The two bacterial isolates were identified as Burkholderia seminalis based on $\operatorname{rec} A$ gene sequence analysis and MLST analysis. Overall, this is the first characterization of $B$. seminalis that cause bacterial fruit rot of apricot.
\end{abstract}

Keywords : apricot fruit rot, Burkholderia cepacia complex, Burkholderia seminalis, Burkholderia vietnamiensis, identification

Bacterial fruit rot of apricot (Prunus armeniaca) (BFRA) has been first reported in China in 2009 and ascribed to Burkholderia cepacia based on carbon source utilization profile, fatty acid methyl esters and analysis of $16 \mathrm{~S}$ rRNA gene sequence (Fang et al., 2009). However, B. cepacia has been regarded as a genetically distinct but phenotypically

\footnotetext{
*Co-corresponding authors.

Guanlin Xie

Phone) +86-571-86971412, FAX) +86-571-86971680

E-mail)glxie@zju.edu.cn

Guochang Sun

Phone) +86-571- 86404073, FAX) +86-571- 86404225

E-mail)sungc@zaas.org
}

similar bacteria group referring to Burkholderia cepacia complex (Bcc) (Fang et al., 2007, 2010; Mahenthiralingam et al., 2008; Zhang and Xie, 2007). Therefore, it is very necessary to determine the precise taxonomic position of the BFRA isolates in the Bcc by a variety of phenotypic and molecular analyses.

The Bcc currently comprises B. cepacia, Burkholderia multivorans, Burkholderia cenocepacia, Burkholderia stabilis, Burkholderia vietnamiensis, Burkholderia dolosa, Burkholderia ambifaria, Burkholderia anthina, Burkholderia pyrrocinia and Burkholderia ubonensis (Coenye and Vandamme, 2003; Mahenthiralingam et al., 2008; Vermis et al., 2002). In addition, Vanlaere et al. (2008, 2009) recently proposed seven new species, namely Burkholderia latens, Burkholderia diffusa, Burkholderia arboris, Burkholderia seminalis, Burkholderia metallica, Burkholderia contaminans and Burkholderia lata. However, it is still unclear whether the BFRA isolates belong to one of these species or may represent a new and separate species of the Bcc.

The objective of this study was to identify and characterize the BFRA isolates by a combination of speciesspecific PCR tests, recA-HaeIII restriction fragment length polymorphism (RFLP) assays, rep-PCR genomic fingerprinting, $r e c A$ gene sequencing, and multilocus sequence typing (MLST) analysis as well as proteolytic activity. In addition, the cable pilin gene $(c b l A)$ and the $B$. cepacia epidemic strain marker (esmR) were detected among the BFRA isolates for the two genetic markers have been associated to the high transmissibility and virulence of some Bcc strains.

\section{Materials and Methods}

Bacterial strains and culture conditions. Two BFRA strains Bca 0901 and Bca 0902 were isolated from the fruit of apricot in our previous study (Fang et al., 2009). The reference strain LMG $1222^{\mathrm{T}}$ of $B$. cepacia was provided by 
the Belgian Co-ordinated Collections of Microorganisms, $\mathrm{BCCM}$, Gent, Belgium. In addition, the Bcc strains representative of different species were included in this study, which were isolated from the rhizosphere of rice (Zhang and Xie, 2007) and cystic fibrosis patients in China (Fang et al., 2010). All strains were maintained on nutrient agar medium (5 $\mathrm{g}$ of peptone, $1 \mathrm{~g}$ of beef extract, $2 \mathrm{~g}$ of yeast extract, $5 \mathrm{~g}$ of sodium chloride, and $15 \mathrm{~g}$ of agar per liter, $\mathrm{PH}$ 7.0). The incubation temperature for growth of bacterial strains was $30^{\circ} \mathrm{C}$.

Species-specific PCR analysis. Total DNAs of bacterial isolates were extracted according to the method of $\mathrm{Li}$ et al. (2006, 2008). The putative species status of the BFRA isolates were determined by species-specific PCR tests, according to the procedures described previously (Mahenthiralingam et al., 2000). PCR reactions were performed with a Programmable Temperature Cycler (PTC-200, MJ Research, USA).

$\boldsymbol{R e c} \boldsymbol{A}$-based RFLP analysis. Amplification of the recA gene was carried out by PCR as described by Zhang and Xie (2007) using the specific primers for Bcc, BCR1 and BCR2. RecA-RFLP was performed according to the method described previously (Lee and Chan, 2007; Mahenthiralingam et al., 2000). After amplification, $8 \mu \mathrm{l}$ of amplified product was digested by $1 \mathrm{U}$ of HaeIII (Fermentas, USA) in a total volume of $15 \mu \mathrm{l}$ and incubated at $37^{\circ} \mathrm{C}$ for $3 \mathrm{~h}$. The RFLP products were separated by $2 \%$ agarose gel electrophoresis and visualized by staining with ethidium bromide. A 100bp ladder (Fermentas, USA) was used as a molecular size marker. The RFLP patterns were manually analyzed and compared to those shown by Bcc reference strains (Mahenthiralingam et al., 2000).

Rep-PCR genomic fingerprinting. The rep-PCR of bacterial isolates and horizontal agarose gel electrophoresis of the PCR products was performed as described by Gevers et al. (2001) and Sahin et al. (2003). The rep-PCR oligonucleotide primers evaluated in this study were REP1R-I (5'-IIIICGICGICATCIGGC-3') and REP2-I (5'-IIICGNCGNCATCNGGC-3'), ERIC 1R (5'-ATGTAAGCTCCTGGGGATTCAC-3') and ERIC2 (5'-AAGTAAGTGA CTGGGGTGAGCG-3'), BOXA1R (5'-CTACGGCAAGGCGACGCTGACG-3'), and (GTG) (5'-GTGGTGGTGGTGGTG3') (Louws et al., 1995; Versalovic et al., 1994). PCR amplification was performed with a Peltier thermal cycler PTC-200 (MJ Research, Watertown, MA, USA) by using the following cycles: 1 initial cycle at $95^{\circ} \mathrm{C}$ for $7 \mathrm{~min} ; 30$ cycles of denaturation at $94^{\circ} \mathrm{C}$ for $1 \mathrm{~min}$, annealing at 44 , 52,53 , or $40^{\circ} \mathrm{C}$ for $1 \mathrm{~min}$ with REP, ERIC, BOX, and $(\mathrm{GTG})_{5}$ primers, respectively, and extension at $65^{\circ} \mathrm{C}$ for 8 min with a single final extension cycle at $65^{\circ} \mathrm{C}$ for $15 \mathrm{~min}$ and a final soak at $4^{\circ} \mathrm{C}$. Analysis of the rep-PCR fingerprint profiles were done using the simple matching similarity coefficient and unweighted pair group with arithmetic averages using NTSYS-pc version 2.02e (Nazari et al., 2007; Versalovic et al., 1994).

DNA sequencing and phylogenetic analysis. PCR amplified product of the recA genes of the BFRA isolates were purified from the gel using AxyPrep DNA Gel Extraction Kit (Axygen BioSciences, USA) and cloned into pGEM-T Easy vector (Promega Co., Madison, WI, USA) according to the supplier's instructions and transferred into Escherichia coli $(\mathrm{DH} 5 \alpha)$ cells. Clones with the correct insert were sequenced as described by Lee et al. (2009). Raw sequences were assembled using the SeqMan program and analyzed with the MegAlign programs (DNASTAR Inc., USA) as described by Jeon et al. (2006, 2008). Sequence identity was confirmed by analysis using the basic local alignment sequence tool (BLAST) at the National Center for Biotechnology Information (NCBI, Bethesda, Md.).

Phylogenetic analysis was performed on the $r e c A$ sequence of the two BFRA isolates and 38 previously published Bcc recA gene (Baldwin et al., 2005; Coenye and Vandamme, 2003; Mahenthiralingam et al., 2000; Payne et al., 2005; Vandamme et al., 2002; Zhang and Xie, 2007). Nucleotides of the recA gene were aligned using CLUSTAL W. Phylogenetic and molecular evolutionary analyses were conducted using the genetic distance-based neighborjoining algorithms within MEGA version 4.0 (http://www. megasoftware.net/). Bootstrap analysis for 1000 replicates was performed to estimate the confidence of tree topology. Pseudomonas aeruginosa was used as the outgroup.

MLST analysis. Seven genetic loci ( $a t p D$, gltB, gyr $B$, $\operatorname{rec} A, \operatorname{lep} A$, phaC and $\operatorname{trp} B$ ) of the BFRA isolates were amplified and sequenced by primers described previously (Baldwin et al., 2005). The forward and reverse sequences of a given locus were aligned, trimmed to the desired allele length using SeqMan II (DNA Star software) and compared with existing alleles in the Bcc MLST database at http:// pubmlst.org/bcc (Jolley et al., 2004). Alleles were assigned arbitrary numbers for each locus and then the allelic proles were compared using the MLST database in order to assign each isolate allelic prole with a sequence type (ST), or obtained new arbitrary numbers and new STs by depositing the new allele-profiles and isolate-profiles to MLST database. The different ST is an indicative of each genetically distinct strain (Baldwin et al., 2005).

A phylogenetic tree of concatenated sequences (2773 $\mathrm{bp}$ ), including fragments of those seven genes from each isolate was constructed based on the neighbour-joining 
method using MEGA software package version 4.0 (Baldwin et al., 2005; Kumar et al., 2004). The significance of branching within the trees was evaluated by bootstrap analysis of 1000 computer-generated trees. Burkholderia pseudomallei was used as the outgroup. This publication made use of the Bcc MLST website (http://pubmlst.org/ bcc/) developed by Keith Jolley and sited at the University of Oxford (Jolley et al., 2004).

Detection of putative transmissibility markers. The detection of the two putative transmissibility markers ( $c b l A$ and $e s m R$ ) on the genome of the Bcc isolates was carried out by PCR as described previously (Clode et al., 2000; Mahenthiralingam et al., 1997). The 1.4-kb esmR gene was amplified with primers BCESM1/BCESM2, while the 664bp cblA gene was amplified using primers CBL1/CBL2. Amplication reaction were carried out using Programmable Temperature Cycler for 25 cycles of $15 \mathrm{~s}$ at $95^{\circ} \mathrm{C}, 1 \mathrm{~min}$ at $63^{\circ} \mathrm{C}$ for detection of esmR or at $55^{\circ} \mathrm{C}$ for detection of $c b l A$, $5 \mathrm{~min}$ at $70^{\circ} \mathrm{C}$ and then a final extension of $10 \mathrm{~min}$ at $70^{\circ} \mathrm{C}$ was applied to all thermal cycles.

Protease assays. Protease production of the Bcc isolates was performed on brain heart infusion (BHI) milk medium as described by Sokol et al. (1979) with minor modification. BHI milk medium was prepared by dissolving 18.5 $\mathrm{g}$ of BHI broth (Difco, USA) and $7.5 \mathrm{~g}$ agar (Difco, USA) in $400 \mathrm{ml}$ of water. One hundred milliliter of $15 \%$ (wt/vol) solution of skim milk (Guangming, Heilongjiang, China) was prepared, and the solutions were autoclaved separately. These two sterile solutions were mixed at $60^{\circ} \mathrm{C}$. A $10 \mathrm{ml}$ volume was dispensed into Petri plates. The bacterial isolates were inoculated on BHI agar with a sterile toothpick. Protease activity was determined by measuring the dia- meter (mm) of zone of clearing around the site of inoculation after incubating the plates for $24 \mathrm{~h}$ and $48 \mathrm{~h}$ at $30^{\circ} \mathrm{C}$. Each treatment had four replicates, and the experiment was performed twice.

\section{Results and Discussion}

Species-specific analysis. Bacterial isolates were confirmed as Bcc by PCR amplification of the $\operatorname{rec} A$ gene with specific primers for Bcc, BCR1 and BCR2 while an amplicon of about $1,041 \mathrm{bp}$ was obtained from the two BFRA isolates. Species-specific PCR tests indicated that the two BFRA isolates and the reference strains of $B$. vietnamiensis gave positive amplifications with primers specific for $B$. vietnamiensis (Table 1). However, amplification of the two BFRA isolates with primers specific for $B$. anthina produced two amplicons of about $500 \mathrm{bp}$ and 1000 bp (Table 1).

The results of this study support the general conclusion that the $r e c A$ gene has proven very useful in discriminating Bcc from closely related species (Mahenthiralingam et al., 2000). Compared to the $16 \mathrm{~S}$ rRNA gene, $\operatorname{rec} A$ (RecA is a protein essential for repair and recombination of DNA) has been shown to be diploid, with a single copy of the gene residing on each of the two large chromosomes present in Bcc strains. If both copies of recA are identical, they may form a more robust platform upon which to base diagnostic PCR probes than the multicopy rRNA genes (Mahenthiralingam et al., 2000). However, this result is in contrast with the result of Mahenthiralingam et al. (2000), who found that species-specific PCR were able to distinguish the former nine species within Bcc. Therefore, it could be suggested that the BFRA isolates did not belong to one of these species.

Table 1. Species-specific PCR analysis of the isolates Bca 0901 and Bca 0902 causing bacterial fruit rot of apricot

\begin{tabular}{|c|c|c|c|c|c|c|c|}
\hline \multirow{2}{*}{ Species-specific primers } & \multicolumn{2}{|c|}{ The apricot isolates } & \multicolumn{5}{|c|}{ B. vietnamiensis strains ${ }^{\mathrm{a}}$} \\
\hline & Bca 0901 & Bca 0902 & 419 & 430 & 440 & $\mathrm{~S} 13$ & $\mathrm{~S} 23$ \\
\hline Burkholderia cepacia & - & - & - & - & - & - & - \\
\hline B. multivorans & - & - & - & - & - & - & - \\
\hline B. сепосерасіа IIIA & - & - & - & - & - & - & - \\
\hline B. cenocepacia IIIB & - & - & - & - & - & - & - \\
\hline B. stabilis & - & - & - & - & - & - & - \\
\hline B. vietnamiensis & + & + & + & + & + & + & + \\
\hline B. dolosa & - & - & - & - & - & - & - \\
\hline B. ambifaria & - & - & - & - & - & - & - \\
\hline B. anthina & $+^{\mathrm{b}}$ & $+^{\mathrm{b}}$ & - & - & - & - & - \\
\hline
\end{tabular}

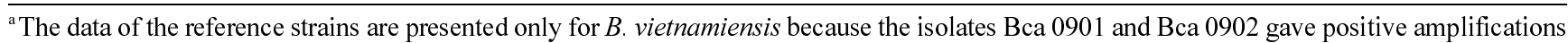
with primers specific for $B$. vietnamiensis.

${ }^{\mathrm{b}}$ An amplicon of about 500 bp specific to B. anthina was obtained from the isolates Bca 0901 and Bca 0902 while another amplicon of about $1000 \mathrm{bp}$ was also obtained. 


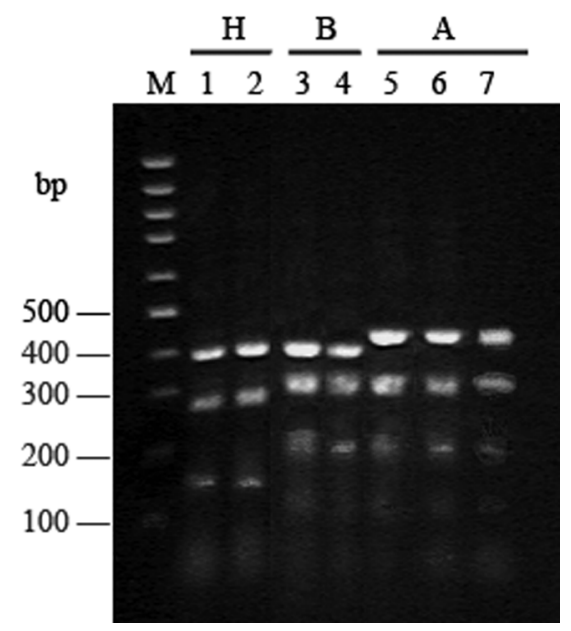

Fig. 1. RecA-HaeIII RFLP assays of the isolates Bca 0901 and Bca 0902 causing bacterial fruit rot of apricot and the five reference strains of $B$. vietnamiensis with the enzyme HaeIII. The DNA molecular size standard is in lane $\mathrm{M}$. The Bcc isolates in each lane are as follows (second lane; left to right): Bca 0901; Bca 0902; B. vietnamiensis strains S13, S23, 419, 430, and 440. The alphabetical HaeIII RFLP type is shown above each lane.

RecA-based RFLP. Digestion with HaeIII of recA gene of the two BFRA isolates resulted in a restriction pattern $\mathrm{H}$, while digestion with HaeIII of $r e c A$ gene of the reference strains of $B$. vietnamiensis resulted in restriction patterns $A$ and B (Fig. 1). This result is consistent with the result of Vandamme et al. (2002), who revealed that recA-HaeIII RFLP types A and B represent $B$. vietnamiensis. However, it is well known that restriction pattern $\mathrm{H}$ was often observed for B. cenocepacia IIIB, B. diffusa, B. arboris and $B$. seminalis strains (Mahenthiralingam et al., 2000; Vanlaere et al., 2008), while these closely related species were able to be differentiated by comparing the sequences of the rec $A$ gene. The result of $r e c A$-RFLP is contrary with the result of recA-based species-specific PCR, which may be attributed to the complexity of the two BFRA isolates.

Rep-PCR genomic fingerprinting. Patterns of PCR products visualized over UV light by ethidium staining for BOX, ERIC, $(\mathrm{GTG})_{5}$, and REP primers are shown in Fig. $2 \mathrm{a}, 2 \mathrm{~b}, 2 \mathrm{c}$ and $2 \mathrm{~d}$, respectively. The use of BOX and ERIC primers resulted in a banding pattern containing approximately $5 \sim 7$ and $7 \sim 13$ visualized PCR products, respectively, while the (GTG) $)_{5}$ and REP primer generated fingerprints containing approximately $4 \sim 6$ and $2 \sim 7$ visualized PCR products, respectively. The dendrogram of combined data produced using BOX, ERIC, (GTG), and REP primers is shown in Fig. 3. Cluster analysis of data resulting from profiles generated by rep-PCR revealed that the two BFRA isolates and the five reference strains of $B$. vietnamiensis
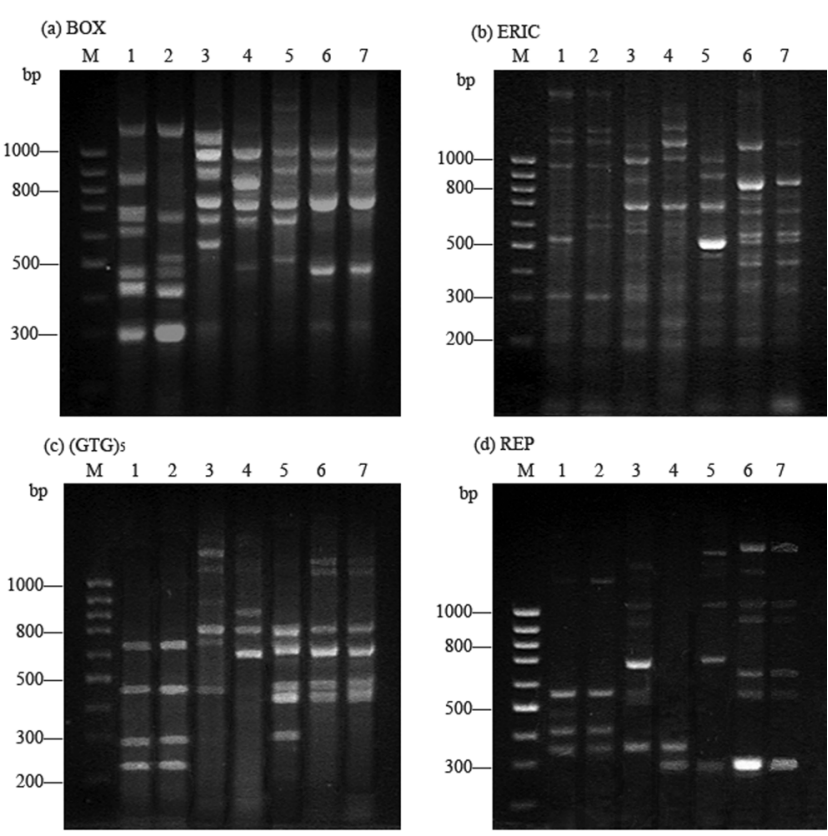

Fig. 2. Rep-PCR fingerprinting assays of the isolates Bca 0901 and Bca 0902 causing bacterial fruit rot of apricot and the five reference strains of B. vietnamiensis. (A) BOX-PCR; (B) ERICPCR; (C) (GTG) 5 -PCR; (D) REP-PCR. The DNA molecular size standard is in lane $\mathrm{M}$. The Bcc isolates in each lane are as follows (second lane; left to right): Bca 0901; Bca 0902; B. vietnamiensis S13, S23, 419, 430, and 440.

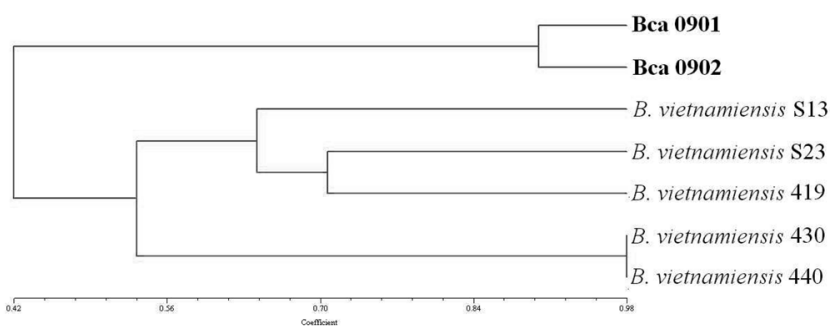

Fig. 3. Dendrogram of genetic relatedness of the combined repPCR data inferred using primers BOX, ERIC, (GTG) $)_{5}$, and REP and generated by the isolates Bca 0901 and Bca 0902 causing bacterial fruit rot of apricot and the five reference strains of $B$. vietnamiensis. The scale indicates the degree of genetic relatedness between Bcc strains.

clustered into two groups and the average genetic similarity between the two groups was 0.42 (Fig. 3), which indicated that the BFRA isolates were genetically different from $B$. vietnamiensis strains, although they both gave positive amplifications with primers specific for $B$. vietnamiensis. In addition, more variation was found within $B$. vietnamiensis strains (average similarity coefficient 0.71 ) than in the two BFRA isolates (0.90).

DNA sequencing and phylogenetic analysis. To defini- 


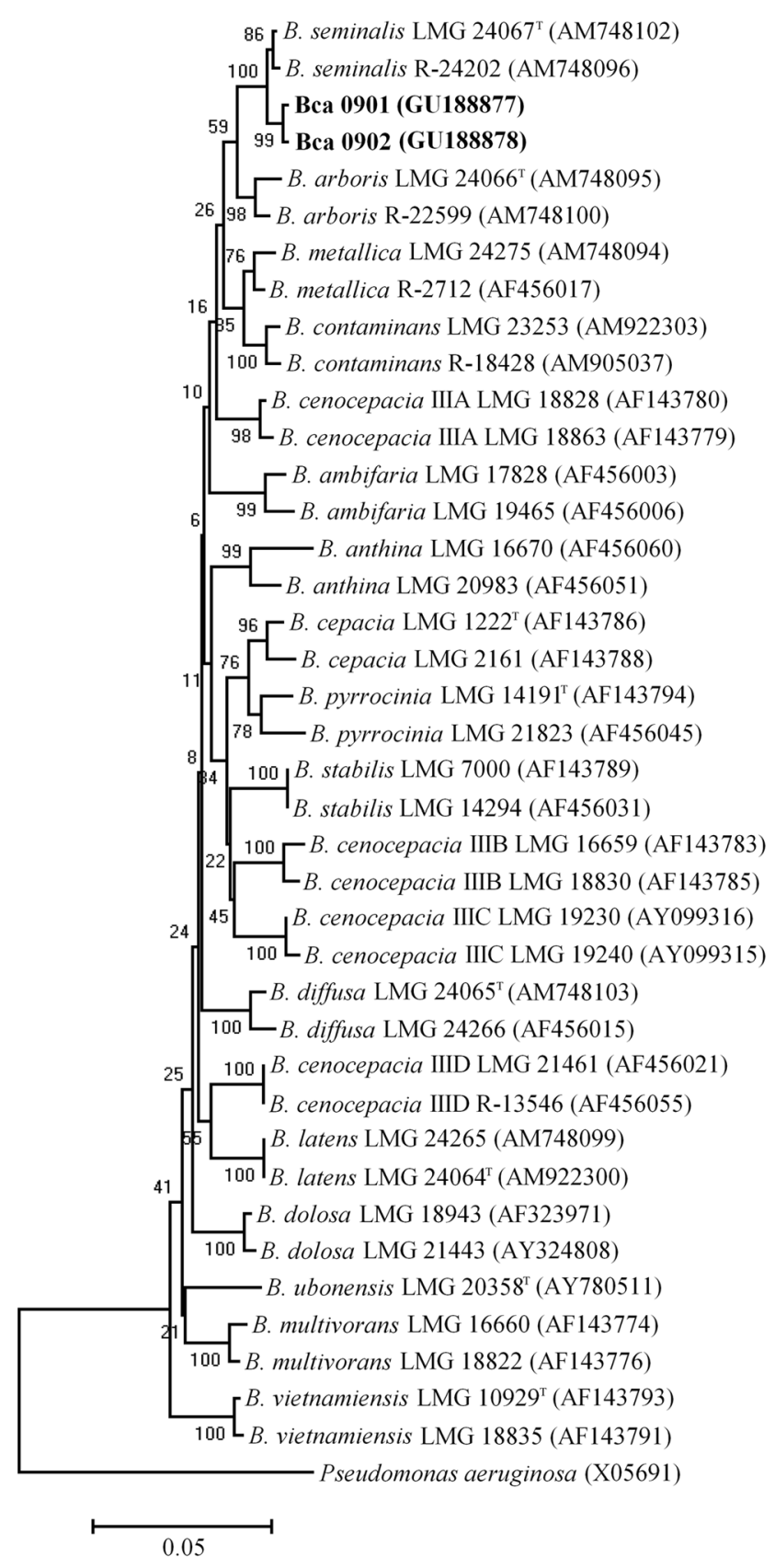

Fig. 4. Phylogenetic tree derived from the recA gene sequence analysis on reference strains of each Burkholderia cepacia complex species and the isolates Bca 0901 and Bca 0902 causing bacterial fruit rot of apricot. The tree was generated by the neighbor-joining method based on the two-parameter Kimura correction of evolutionary distances. Bootstrap analyses (1000 replicates) for node values from $50 \%$ are indicated. Pseudomonas aeruginosa was used as the outgroup. Bar, $1 \%$ sequence dissimilarity.

tively assess the species status of the two BFRA isolates, the complete recA gene sequences were determined and aligned to other known Bcc sequences deposited in Gen-

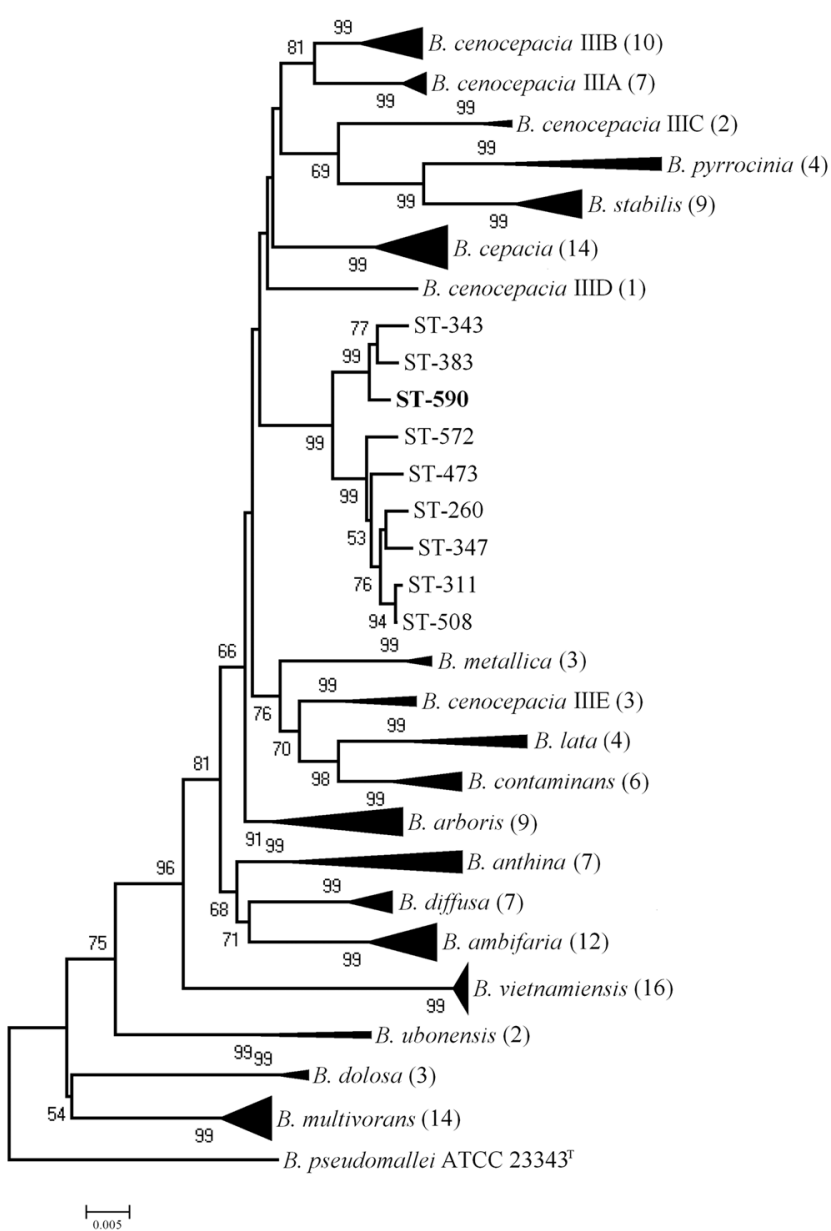

Fig. 5. Phylogenetic tree of concatenated nucleotide sequences from seven loci ( $a t p D, g l t D, g y r B$, recA, lepA, phaC and trpB) of Bcc bacteria and the isolates Bca 0901 and Bca 0902 causing bacterial fruit rot of apricot. The tree was generated by the neighbor-joining method based on the two-parameter Kimura correction of evolutionary distances. Bootstrap analyses (1000 replicates) for node values from $50 \%$ are indicated. Burkholderia pseudomallei ATCC $23343^{\mathrm{T}}$ was used as the outgroup. Bar, 1\% sequence dissimilarity.

Bank. All sequences obtained were more than $96 \%$ similar to those of other members of the Bcc. The phylogenetic analysis revealed that the BFRA isolates and strains of $B$. seminalis clustered within a group and well separated from other species of Bcc (Fig. 4). It is therefore considered that the BFRA isolates should be identified as B. seminalis.

The result of phylogenetic analysis based on the recA gene sequence explained the differences in recA-RFLP and rep-PCR profiles between the two BFRA isolates and the $B$. vietnamiensis strains. However, species-specific primers were unavailable for the new proposed Bcc species including $B$. seminalis. Surprisingly, the BFRA isolates were unable to be differentiated from the strains of $B$. vietnamiensis based on the available species-specific primers, 
indicating the complexity of the Bcc isolates.

MLST analysis. MLST analysis showed that the BFRA isolates Bca 0901 and Bca 0902 had a unique sequence type ST-590, which was novel when compared with existing STs in the MLST database. Concatenated nucleotide sequences $(2,773 \mathrm{bp})$ for $141 \mathrm{Bcc}$ STs to assess the relationships between the two BFRA isolates and different species of Bcc were analyzed using a neighbor joining tree (Fig. 5). Comparisons of the topology of neighbor-joining trees for the nucleotide sequence of the novel ST-590 clustered closely with STs belonged to B. seminalis (ST$260,-311,-343,-347,-383,-473,-508,-572)$ with $100 \%$ bootstrap values.

The MLST results were consistent with the result of phylogenetic analysis of the $\operatorname{rec} A$ gene sequence, indicating that the two BFRA isolates belong to $B$. seminalis. Many researches have shown that MLST is a simple sequencing tool that uncovers allelic variants in conserved genes for the purpose of characterizing, typing, and classifying members of bacterial populations (Curran et al., 2004; Godoy et al., 2003). In agreement with the result of Vanlaere et al. (2008), this present study demonstrated that the MLST method was able to clearly differentiate all existing species in the closely related Bcc. In addition, the two BFRA isolates could be effectively identified by this simple, widely used technique that is directly comparable via the Internet.

Transmissibility marker genes. Pathogenic Bcc strains can sometimes be distinguished from nonpathogenic strains by examining the existence of transmissibility markers (Parke and Gurian-Sherman, 2001). Therefore, two transmissibility factors associated with the highly transmissible epidemic strains of $B$. cenocepacia were analyzed by PCR amplification. However, no $c b l A$ and $e s m R$ marker genes were detected from the two BFRA isolates and $B$. cepacia LMG $1222^{\mathrm{T}}$ as well as the five reference strains of $B$. vietnamiensis (data not shown).

Protease assay. The zone diameter of hydrolysis around colonies of the BFRA isolates Bca 0901 and Bca 0902 were $1.5 \mathrm{~mm}$ and $0.7 \mathrm{~mm}$, respectively, while the zone diameter of hydrolysis around colonies of B. cepacia LMG $1222^{\mathrm{T}}$ was $0.5 \mathrm{~mm}$ on the BHI milk plates after $24 \mathrm{~h}$ incubation (Table 2). However, no visible zone of hydrolysis was observed around colonies of the five reference strains of $B$. vietnamiensis. The zone diameter of hydrolysis around colonies of the BFRA isolates Bca 0901 and Bca 0902 were $3.3 \mathrm{~mm}$ and $3.0 \mathrm{~mm}$, respectively, while the zone diameter of hydrolysis around colonies of B. cepacia LMG $1222^{\mathrm{T}}$ was $2.3 \mathrm{~mm}$ after $48 \mathrm{~h}$ incubation (Table 2 ). In addition, the
Table 2. Proteolytic activity of the isolates Bca 0901 and Bca 0902 causing bacterial fruit rot of apricot by inoculating them on brain heart infusion milk medium after inocubation of $24 \mathrm{~h}$ and $48 \mathrm{~h}$

\begin{tabular}{lcc}
\hline \hline \multirow{2}{*}{ Bcc strains } & \multicolumn{2}{c}{$\begin{array}{c}\text { Zones of clearing }(\mathrm{mm})^{\mathrm{a}} \\
\text { after incubation of }\end{array}$} \\
\cline { 2 - 3 } & $24 \mathrm{~h}$ & $48 \mathrm{~h}$ \\
\hline Bca 0901 & $1.5 \pm 0.29$ & $3.3 \pm 0.33$ \\
Bca 0902 & $0.7 \pm 0.33$ & $3.0 \pm 0.00$ \\
B. cepacia LMG $1222^{\mathrm{T}}$ & $0.5 \pm 0.50$ & $2.3 \pm 0.33$ \\
B. vietnamiensis 419 & $0.0 \pm 0.00$ & $0.2 \pm 0.17$ \\
B. vietnamiensis 430 & $0.0 \pm 0.00$ & $0.2 \pm 0.17$ \\
B. vietnamiensis 440 & $0.0 \pm 0.00$ & $0.0 \pm 0.00$ \\
B. vietnamiensis $\mathrm{S} 13$ & $0.0 \pm 0.00$ & $0.0 \pm 0.00$ \\
B. vietnamiensis $\mathrm{S} 23$ & $0.0 \pm 0.00$ & $0.0 \pm 0.00$
\end{tabular}

${ }^{\mathrm{a}}$ Zones of clearing were measured from edge of colony to edge of clearing.

zone diameter of hydrolysis around colonies of $B$. vietnamiensis strain 419 and 430 were $0.2 \mathrm{~mm}$, while no visible zone of hydrolysis was observed around colonies of the other $B$. vietnamiensis strains.

In agreement with this result, Gingues et al. (2005) found that B. cepacia $\mathrm{LMG} 1222^{\mathrm{T}}$, an onion pathogen, shows proteolytic activity. In addition, Ludovic et al. (2007) revealed that a majority of Bcc isolates produce extracellular proteases. Interestingly, strains deficient in protease production are less virulent than the parental B. pseudomallei strain in diabetes-induced Sprague-Dawley rats, a lung infection model (Sexton et al., 1994). In this study, the plant pathogenic bacteria including the BFRA isolates and B. cepacia LMG $1222^{\mathrm{T}}$ showed a higher proteolytic activity compared with that of the non-pathogenic B. vietnamiensis strains, which is consistent with the result of McKevitt et al. (1989), who found that protease can be considered to be one of the virulence determinants of Bcc species.

In summary, our results clearly demonstrated that the BFRA isolates Bca 0901 and Bca 0902 had strong proteolytic activity and were identified as $B$. seminalis based on rec $A$-RFLP and rep-PCR profiles as well as rec $A$ gene sequence analysis and MLST analysis. However, the two BFRA isolates were unable to be differentiated from the strains of $B$. vietnamiensis based on species-specific primers. To date, no $B$. seminalis strains have been reported as plant pathogen. This is the first characterization of $B$. seminalis that cause bacterial fruit rot of apricot.

\section{Acknowledgements}

This project was supported by Zhejiang Provincial Natural Science Foundation of China (Y3090150), the Fundamental Research Funds for the Central Universities (KYJD09022), 
the Agricultural Ministry of China (nyhyzx200803010) and Specialized Research Fund for the Doctoral Program of Higher Education (20090101120083).

\section{References}

Baldwin, A., Mahenthiralingam, E., Thickett, K. M., Honeybourne, D., Maiden, M. C. J., Govan, J. R., Speert, D. P., LiPuma, J. J., Vandamme, P. and Dowson, C. G. 2005. Multilocus sequence typing scheme that provides both species and strain differentiation for the Burkholderia cepacia complex. $J$. Clin. Microbiol. 43:4665-4673.

Clode, F. E., Kaufmann, M. E., Malnick, H. and Pitt, T. L. 2000. Distribution of genes encoding putative transmissibility factors among epidemic and nonepidemic strains of Burkholderia cepacia from cystic brosis patients in the United Kingdom. $J$. Clin. Microbiol. 38:1763-1766.

Coenye, T. and Vandamme, P. 2003. Diversity and signicance of Burkholderia species occupying diverse ecological niches. Environ. Microbiol. 5:719-729.

Curran, B., Jonas, D., Grundmann, H., Pitt, T. and Dowson, C. G. 2004. Development of a multilocus sequence typing scheme for the opportunistic pathogen Pseudomonas aeruginosa. $J$. Clin. Microbiol. 42:5644-5649.

Fang, Y., Li, B., Wang, F., Liu, B. P., Wu, Z. Y., Qiu, W. and Xie, G. L. 2009. Bacterial fruit rot of apricot caused by Burkholderia cepacia in China. Plant Pathol. J. 25:429-432.

Fang, Y., Lou, M. M., Li, B., Xie, G. L., Wang, F., Zhang, L. X. and Luo, Y. C. 2010. Characterization of Burkholderia cepacia complex from cystic fibrosis patients in China and their chitosan susceptibility. World J. Microbiol. Biotechnol. 26: 443-450.

Fang, Y., Zhang, L. X. and Xie, G. L. 2007. Internal bacterial rot of onion bulbs caused by Burkholderia cepacia in China. $J$. Plant Pathol. 89:294.

Gevers, D., Huys, G and Swings, J. 2001. Applicability of repPCR fingerprinting for identification of Lactobacillus species. FEMS Microbiol. Lett. 205:31-36.

Gingues, S., Kooi, C., Visser, M. B., Subsin, B. and Sokol, P. A. 2005. Distribution and expression of the ZmpA metalloprotease in the Burkholderia cepacia complex. J. Bacteriol. 187:8247-8255.

Godoy, D., Randle, G, Simpson, A. J., Aanensen, D. M., Pitt, T. L., Kinoshita, R. and Spratt, B. G. 2003. Multilocus sequence typing and evolutionary relationships among the causative agents of melioidosis and glanders, Burkholderia pseudomallei and Burkholderia mallei. J. Clin. Microbiol. 41:2068-2079.

Jeon, Y. H., Chang, S. P., Kim, S. G. and Kim, Y. H. 2006. Halo blight of kudzu vine caused by Pseudomonas syringae pv. phaseolicola in Korea. Plant Pathol. J. 22:119-124.

Jeon, Y. H., Park, H., Lee, B. D., Yu, Y. H., Chang, S. P., Kim, S. G, Hwang, I. and Kim, Y. H. 2008. First description of crown gall disease on ginseng. Plant Pathol. J. 24:207-210.

Jolley, K. A., Chan, M. S. and Maiden, M. C. 2004. mlstdbNet distributed multi-locus sequence typing (MLST) databases. BMC Bioinform. 5:86.
Kumar, S., Tamura, K. and Nei, M. 2004. MEGA3: integrated software for molecular evolutionary genetics analysis and sequence alignment. Brief. Bioinform. 5:150-163.

Lee, Y. A. and Chan, C. W. 2007. Molecular typing and presence of genetic markers among strains of banana finger-tip rot pathogen, Burkholderia cenocepacia, in taiwan. Phytopathology $97: 195$.

Lee, Y. S., Han, H. S., Kim, G. H., Koh, Y. J., Hur, J. S. and Jung, J. S. 2009. Causal agents of blossom blight of Kiwifruit in Korea. Plant Pathol. J. 25:220-224.

Li, B., Xie, G L., Zhang, J. Z., Janssens, D. and Swings, J. 2006. Identification of the bacterial leaf spot pathogen of poinsettia in China. J. Phytopathol. 154:711-715.

Li, B., Xu, L. H., Lou, M. M., Li, F., Zhang, Y. D. and Xie, G L. 2008. Isolation and characterization of antagonistic bacteria against bacterial leaf spot of Euphorbia pulcherrima. Lett. Appl. Microbiol. 46:450-455.

Louws, F. J., Fulbright, D. W., Stephens, C. T. and de Bruijn, F. J. 1995. Determination of genomic structure by rep-PCR fingerprinting to rapidly classify Xanthomonas campestris pv. vesicatoria. Phytopathology 85:528-536.

Ludovic, V., Groleau, M. C., Dekimpe, V. and Deziel, E. 2007. Burkholderia diversity and versatility: an inventory of the extracellular products. J. Microbiol. Biotechnol. 17:1407-1429.

Mahenthiralingam, E., Baldwin, A. and Dowson, C. G 2008. Burkholderia cepacia complex bacteria: opportunistic pathogens with important natural biology. J. Appl. Microbiol. 104: 1539-1551.

Mahenthiralingam, E., Bischof, J., Byrne, S. K., Radomski, C., Davies, J. E., Av-Gay, Y. and Vandamme, P. 2000. DNAbased diagnostic approaches for identication of Burkholderia cepacia complex, Burkholderia vietnamiensis, Burkholderia multivorans, Burkholderia stabilis, and Burkholderia cepacia genomovars I and III. J. Clin. Microbiol. 38:3165-3173.

Mahenthiralingam, E., Simpson, D. A. and Speert, D. P. 1997. Identication and characterization of a novel DNA marker associated with epidemic Burkholderia cepacia strains recovered from patients with cystic brosis. J. Clin. Microbiol. 35:808-816.

McKevitt, A. I., Bajaksouzian, S., Klinger, J. D. and Woods, D. E. 1989. Purification and characterization of an extracellular protease from Pseudomonas cepacia. Infect. Immun. 57:771-778.

Nazari, F., Niknam, G. R., Ghasemi, A., Taghavi, S. M., Momeni, H. and Torabi, S. 2007. An investigation on strains of Clavibacter michiganensis subsp. michiganensis in north and north west of Iran. J. Phytopathol. 155:563-569.

Parke, J. L. and Gurian-Sherman, D. 2001. Diversity of the Burkholderia cepacia complex and implications for risk assessment of biological control strains. Ann. Rev. Phytopathol. 39:225-258.

Payne, G. W., Vandamme, P., Morgan, S. H., LiPuma, J. J., Coeyne, T., Weightman, A. J., Jones, T. H. and Mahenthiralingam, E. 2005. Development of a recA gene-based identication approach for the entire Burkholderia genus. Appl. Environ. Microbiol. 71:3917-3927.

Sahin, F., Abbasi, P. A., Lewis Ivey, M. L., Zhang, J. and Miller, 
S. A. 2003. Diversity among strains of Xanthomonas campestris pv. vitians from lettuce. Phytopathology 93:64-70.

Sexton, M. M., Jones, A. L., Chaowagul, W. and Woods, D. E. 1994. Purification and characterization of a protease from Pseudomonas pseudomallei. Can. J. Microbiol. 40:903-910.

Sokol, P. A., Ohman, D. E. and Iglewski, B. H. 1979. A more sensitive plate assay for detection of protease production by Pseudomonas aeruginosa. J. Clin. Microbiol. 9:538-540.

Vandamme, P., Henry, D., Coenye, T., Nuzla, S., Vancanneyt, M., LiPuma, J. J., Speert, D. P., Govan, J. R. W. and Mahenthiralingam, E. 2002. Burkholderia anthina sp. nov. and Burkholderia pyrrocinia: two additional Burkholderia cepacia complex bacteria, may confound results of new molecular diagnostic tools. FEMS Immunol. Med. Microbiol. 33:143-149.

Vanlaere, E., Baldwin, A., Gevers, D., Henry, D., Brandt, E. D., LiPuma, J. J., Mahenthiralingam, E., Speert, D. P., Dowson, C. and Vandamme, P. 2009. Taxon K, a complex within the Burkholderia cepacia complex, comprises at least two novel species: Burkholderia contaminans sp. nov. and Burkholderia lata sp. nov. Int. J. Syst. Evol. Microbiol. 59:102-111.
Vanlaere, E., LiPuma, J. J., Baldwin, A., Henry, D., Brandt, E. D., Mahenthiralingam, E., Speert, D. P., Dowson, C. and Vandamme, P. 2008. Burkholderia latens sp. nov., Burkholderia diffusa sp. nov., Burkholderia arboris sp. nov., Burkholderia seminalis sp. nov. and Burkholderia metallica sp. nov., novel species within the Burkholderia cepacia complex. Int. J. Syst. Evol. Microbiol. 58:1580-1590.

Vermis, K., Coenye, T., Mahenthiralingam, E., Nelis, H. J. and Vandamme, P. 2002. Evaluation of species-specic recA-based PCR tests for genomovar level identication within the Burkholderia cepacia complex. J. Med. Microbiol. 51:937940.

Versalovic, J., Schneider, M., de Bruijn, F. J. and Lupski, J. R. 1994. Genomic fingerprinting of bacteria using repetitive sequence based PCR (rep-PCR). Methods Mol. Cell. Biol. 5:25-40.

Zhang, L. X. and Xie, G L. 2007. Diversity and distribution of Burkholderia cepacia complex in the rhizosphere of rice and maize. FEMS Microbiol. Lett. 266:231-235. 